\title{
Effect of Temperature on Sulfonated Poly (Ether Ether Ketone) Blended with Charged Surface Modifying Macromolecule Membrane for DMFCs
}

\author{
A. Mayahi ${ }^{1}$, J. Jaafar ${ }^{2}$, M. N. A. Mohd Norddin ${ }^{3 *} \&$ H. Hassan ${ }^{4}$ \\ ${ }^{1,2 \& 3}$ Advanced Membrane Technology Research Center (AMTEC), Universiti Technologi Malaysia, 81310 Johor \\ Bahrou, Johor, Malaysia \\ ${ }^{4}$ Department of Chenical Engineering, Universiti Téknologi Malaysia, , 81310 Johor Bahru, Johor, Malaysia
}

\begin{abstract}
The purpose of this research was to determine the behavior of modified sulfonated poly (ether ether ketone) (SPEEK) with degree of sulfonation (DS) $68 \%$ blended by charged surface modifying macromolecule (cSMM) at different operating temperatures (room to $80^{\circ} \mathrm{C}$ ) for direct methanol fuet cell application. The fabricated SPEEK (68)/CSMM membrane was compared with SPEEK (68) and Nafion112 membranes in terms of water uptake, proton conductivity, and methanol permeability at relatively high temperatures. The water uptake of SPEEK (68)/ CSMM was higher than that of SPEEK (68) and Nafion1 12 over the temperature ranges studied; however it was dissolved at $80^{\circ} \mathrm{C}$. Proton conductivity of SPEEK (68)/CSMM showed improvement compared to SPEEK (68) at temperature range, but still lower than Nafion 12 , moreover methanol permeability behavior of fabricated membrane was lower at high temperatures as compared to that of SPEEK and Nafion 12 and better overall performance was allocated to the fabricated membrane at $60^{\circ} \mathrm{C}$. These results indicate that SPEEK (68)/CSMM membrane is promising to be used as a proton exchange membrane in direct methanol fuel cell.
\end{abstract}

Keywords: Direct methanol fuel cell, proton exchange membrane, charged surface modifying macromolecule, different operating temperatures

\subsection{INTRODUCTION}

Energy crisis and environment pollution have promoted researchers to find alternative energies instead of fossil fuels. Fuel cell is an alternative energy which has attracted a great deal of attention nowadays [1]. Direct methanol fuel cell (DMFC) is a type of fuel cell which has been studied widely to be used in the notebook computers, cell phones and other electronic devices due to its convenient fuel supply and quick start time[2, 3]. Proton exchange membranes (PEMs) are the heart of fuel cells which should have some criteria to be commercialized: high proton conductivity, low

\footnotetext{
* Corresponding to: M. N. A. Mohd Norddin (email: anam@ petroleum.utm.my)
}

methanol permeability and good mechanical and chemical stabilities[4]. Nafion is considered as the most commercialized PEM in fuel cell industry due to its excellent chemical and electrochemical properties and its high proton conductivity when it is hydrated, however its downsides such as high cost, and high methanol permeability especially at high temperatures have stimulated researchers to consider other possible alternatives [5-9]. Sulfonated poly (ether ether ketone) (SPEEK), Poly (ether sulfone) (PES), and polybenzimide (PBI) are non-fluorinated polymers which possess outstanding criteria such as superior chemical stability, high thermo-oxidative resistance, cheaper prices compare to Nafion and well-behaved mechanical properties [4]. The major issue of SPEEK membrane is beside water uptake 


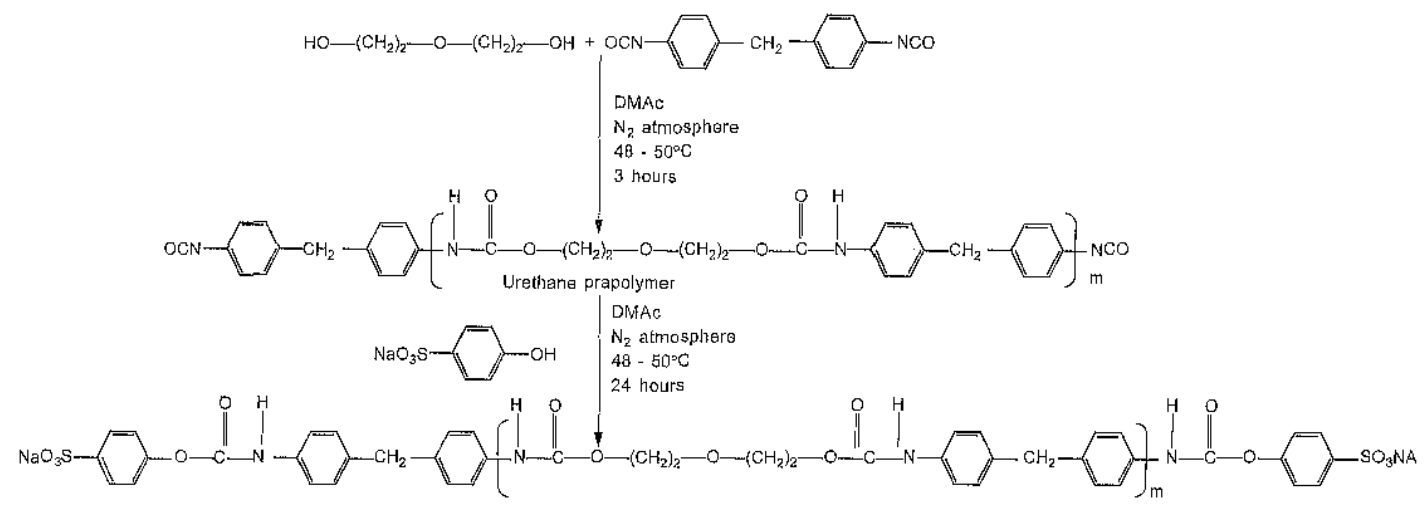

Figure 1 Schematic presentation of the synthesis reaction of CSMM

increment at high temperatures methanol permeability also increases which declines the DMFC performance due to the presence of methanol in the cathode side, however recently DMFC operation at high temperatures has attracted attention due to better proton conductivity, better kinetics of methanol oxidation and improvement of the electrodes tolerance to carbon monoxide[10]. Hence many studies have been .carried out to tackle this issue: crosslinking[1], blending with other polymers [11], adding nanoclay to the base polymer[12], applying inorganic fillers like $\mathrm{BPO}_{4}, \mathrm{SiO}_{2}, \mathrm{TiO}_{2}$ and $\mathrm{ZrO}_{2}$ into SPEEK membrane [13-15] and surface modifying macromolecule (SMM) approach. SMM is a simple blending method which has the concept of polymer segregation in polymer science elsewhere[1618].cSMM is a modified structure of the SMM which possesses sulfonic acid groups. The synthesis of cSMM is shown in Figure 1.

In this study the behavior of SPEEK (68)/ cSMM on water uptake, methanol permeability, and proton conductivity was studied at different temperatures. The membrane also was compared with SPEEK (68) and Nafion112 at relatively high temperatures.

\subsection{EXPERIMENTAL}

\subsection{Materials}

Materials which were used in this study are as follows; PEEK in powder form $(<80 \mathrm{~mm})$ was obtained from Victrex Inc., USA. The weight average molecular weight of poly (ether ether ketone) was $3.92 \times 10^{4}$ and its density was $1.29 \times$ $10^{6} \frac{\mathrm{g}}{\mathrm{cm}^{3}}$. The sulfonation agent is concentrated sulfuric acid (95-97\%) obtained from Merck Co. and it was used as received without further purification. 1-Methyl2-pyrolidinone (NMP, anhydrous 99.5\%) and Methanol, 99.9\% were bought also from Merck Co. Nafion 112 was bought from Dupont de Nemours Co. and CSMM was used as it received.

\subsection{Synthesis of Sulfonated Poly (Ether Ether Ketone)}

PEEK was sulfonated by following technique which is described in $[19,20] .5$ grams of PEEK was dried in a vacuum oven at $100^{\circ} \mathrm{C}$ for $24 \mathrm{hrs}$. and then it was dissolved in $95 \mathrm{ml}$ of concentrated sulfuric acid (95-97\%) at room temperature to suppress the heterogeneous sulfonation. After completing the dissolution of PEEK (about $1 \mathrm{~h}$ ), the polymer solution was brought to the desired temperature 65 and it was hold for $3 \mathrm{~h}$ to obtain the desired degree of sulfonation (DS). In order to terminate the reaction, the polymer solution was poured into excess ice-cold deionized water under continuous stirring for one night to remove the residual acid. The polymer was washed repeatedly with deionized water till a neutral $\mathrm{PH}$ is reached. Thi..: : s dried by air circulation oven at $60^{\circ} \mathrm{C}$ : : 
2.3 Characterization of Sulfonated Poly (Ether Ether Ketone)

A crucial characterization of SPEEK was on the sulfonation degree (DS). It was measured by Hydrogen Nuclear Magnetic Resonance $\left({ }^{1}\right.$ HNMR) (Bruker, USA) at a resonance freqquency of 400.13 $\mathrm{MHz}$ and at room temperature $[19,20]$.

\subsection{Preparation of Membranes}

10 gram of SPEEK was dissolved in 90 gram NMP to make a $10 \mathrm{w} t \%$ of original SPEEK solution. The blend solution was prepared by mixing $0.416 \mathrm{~g}$ of cSMM and 10 gram of SPEEK, to make $4 \mathrm{wt} \%$ of cSMM in total solid. Both are stirred for $24 \mathrm{~h}$, before the mixtures were cast onto a glass plate using a pneumatic casting machine. The membrane was dried at $100^{\circ} \mathrm{C}$ for $24 \mathrm{~h}$ in a vacuum oven. After cooling to room temperature, the membrane was converted into the $\mathrm{H}^{+}$form by immersing it into a $1 \mathrm{M}$ sulfuric acid solution for $24 \mathrm{hrs}$ at the room temperature and blotted dry with absorbent paper before it was air dried [21].

\subsection{Characterization of Membrane}

\subsubsection{Methanol Permeability Measurement at Different Temperatures}

Diaphragm diffusion was used to determine the methanol permeability of the fabricated membrane at different temperature. The apparatus was made of two identical compartments (A and B) which were separated by an effective area of $5.067 \mathrm{~cm}^{2}$. Compartment $\mathrm{A}\left(\mathrm{V}=150 \mathrm{~cm}^{3}\right)$ was filled with $1 \mathrm{M}$ methanol, while compartment $B\left(V=150 \mathrm{~cm}^{3}\right)$ was filled with deionized water. The methanol molecules diffused along the concentration gradiant through the membrane into the opposite compartment. It should be expressed that during the experiment magnetic stirrer was used in each compartments to ensure uniformity. Liquid samples $(500 \mu \mathrm{l})$ were taken every $30 \mathrm{~min}$ to measure methanol concentration changes in compartment B by a digital refractometer (Perkin Elmer, USA). Before testing all membranes were hydrated in de-ionized water for at least $24 \mathrm{~h}$ and the thicknesses in hydrated form were from 54 to $72 \mu \mathrm{m}$. it should be mentioned that methanol diffusion was induced by a concentration gradient across the membrane. Hence, the change of methanol concentration in the diffusion reservoir expressed with below equation, the diffusion coefficient was obtained by following equation [22]:

$$
C_{B}(t)=\frac{A}{V_{B}}-\frac{D K}{L} C_{A}\left(t-t_{0}\right)
$$

Where $C_{B}$ is the methanol concentration in diffusion reservoir $\left(\frac{\mathrm{mol}}{\mathrm{L}}\right)$ at time $t, C_{A}$ is the methanol concentration in feed $\left(\frac{\mathrm{mol}}{\mathrm{L}}\right)$ compartment, $A$ is the effective area of membrane $\left(\mathrm{cm}^{2}\right), L$ is the thickness of membrane $(\mathrm{cm})$, and $V_{E}$ is the volume of diffusion reservoir $\left(\mathrm{cm}^{3}\right)$. The time lag, $t_{0}$ is explicitly related to the diffusivity $\left(t_{0}=\frac{L^{2}}{6 D}\right)$.

Methanol permeability $(\tau)$ is defined as the product of the diffusivity of methanol $(D)$ and the partition coefficient $(K) ; \tau=D K . \tau$ is calculated from the linear interpolation of $C_{B}$ versus $t$ and the slope of the graph ( $m$ ) by equation (2):

$$
\frac{C_{B}(t)}{t-t_{0}}=m
$$

As a consequence equation (3) can be rearranged to calculate the methanol permeability $\left(\frac{\mathrm{cm}^{2}}{\mathrm{~s}}\right)$ as expressed below:

$$
t=m-\frac{V_{B}}{A} \frac{L}{C_{A}}
$$

The Figure 2 shows the apparatus which was used to measure methanol permeability. To control the temperature two digital thermometers were attached to the heater and put in each compartment.

\subsubsection{Proton Conductivity Measurement at Different Temperatures}

The proton conductivity of the membrane was measured by $\mathrm{AC}$ impedance technique using a Solarton 1260 impedance-gain phase analyzer. The impedance spectra recorded over the frequency range of $0.1 \mathrm{~Hz}$ to $10 \mathrm{MHz}$ with 50 


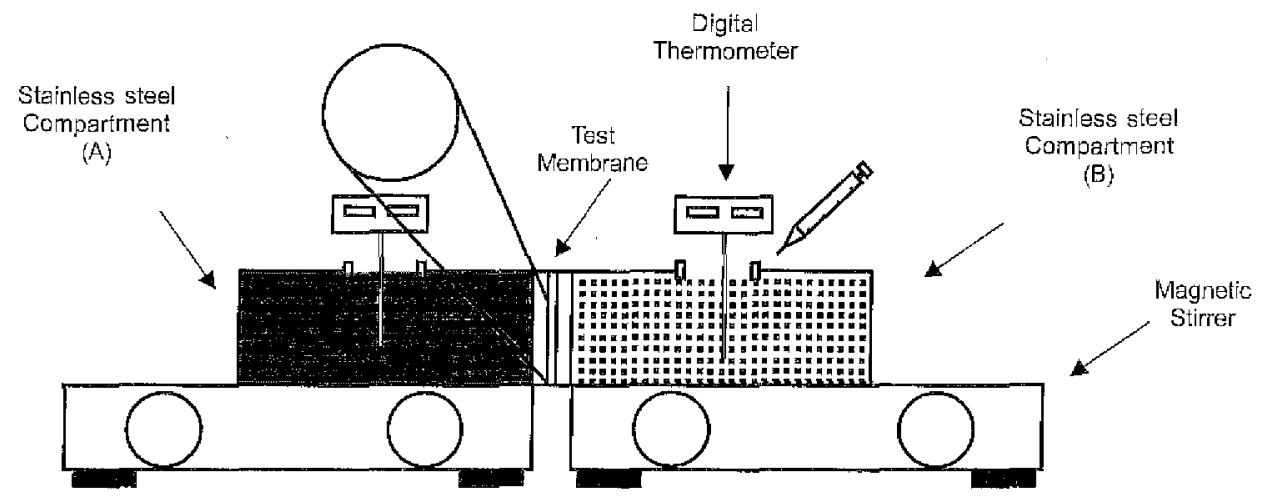

Figure 2 Methanol permeability measurement apparatus

to $500 \mathrm{mV}$ oscillating voltage in $100 \% \mathrm{RH}$ and different temperatures (room to $80^{\circ} \mathrm{C}$ ). Membrane samples with thicknesses between 57 to $74 \mu \mathrm{m}$ equilibrated in deionized water for 24 hrs before being tested. Then, the membranes were placed between two stainless-steel electrodes which had $2.011 \mathrm{~cm}^{2}$ face areas, and then these stainless-steel electrodes and membrane were put in a conductive cell (this cell was used to host the sample tightly). The membrane resistance $(\Omega)$ obtained from the intercept of the impedance curve with the realaxis at the high-frequency end. Finally proton conductivity of membranes were calculated according to below equation [23]:

$$
\sigma=\frac{L}{\Omega S}
$$

$L$ and $S$ are the thickness and face area of the membrane, respectively.

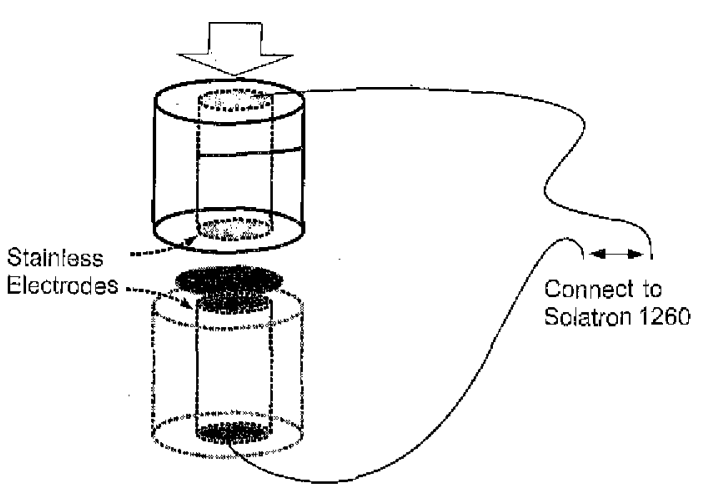

Figure 3 Proton conductivity measurement apparatus

\subsubsection{Water Uptake Measurement at Different Temperatures}

The membranes were dried in an oven at $60^{\circ} \mathrm{C}$ for 48 hrs and weighted ( $W_{\text {drr }}$ ) and then immersed in deionized water at desired temperature. After taking out the membranes the surface water was removed by absorbent paper and membranes were weighted quickly ( $\boldsymbol{W}_{\text {we }}$ ). Finally, \% of water uptake calculated from below equation (5)

$$
\text { Water uptake }=\frac{W_{\text {wet }}-W_{\mathrm{dry}}}{W_{\mathrm{dry}}} \times 100
$$

Where $W_{\text {wet }}$ and $W_{\mathrm{dry}}$ where the weight of the wet and the dry membrane, respectively [21].

\subsubsection{Overall Membrane Characteristic}

The overall membrane characteristic can be determined using the following expression (6) [22]:

$$
\Phi=\frac{\sigma}{P}
$$

Where $\Phi$ is a parameter that evaluate the overall membrane characteristic in terms of the proton conductivity, $\sigma$ to the methanol permeability, $P$.

\subsection{RESULTS AND DISCUSSION}

\subsection{Degree of Sulfonation of Sulfonated Poly (Ether Ether Ketone)}

The degree of sulfonation of the freshly produced SPEEK was determined by H NMR analysis. In 


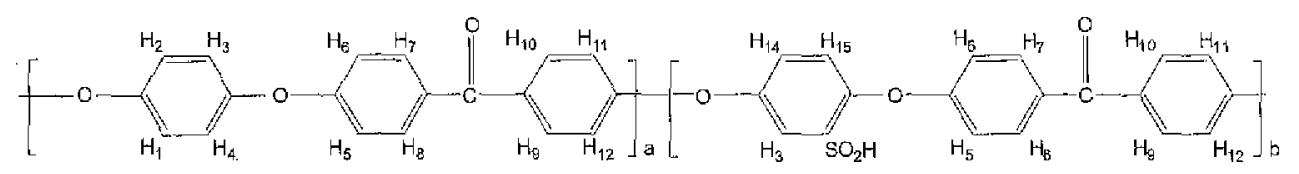

Figure 4 Classification of the aromatic protons SPEEK repeat unit

H NMR spectra it can be seen obviously that presence of sulfonic acid group causes 0.25 downfield signal of $\mathrm{H}_{13}$, compared with $\mathrm{H}_{14}$ and $\mathrm{H}_{15}$ in the hydroquinone ring, resulting in a distinct signal for protons at the 13 position.

The classification of the aromatic protons for the SPEEK repeat unit is according to Figure 4.

The intensity of $\mathrm{J}_{13}$ is equivalent to the $\mathrm{SO}_{3} \mathrm{H}$ group content. The $\mathrm{H}$ NMR signal for $\mathrm{SO}_{3} \mathrm{H}$ is difficult to be recorded directly due to the fact that the proton is able to change its position [24]. The DS can be calculated by below equation

$$
\frac{\mathrm{DS}}{\mathrm{S}-2 \mathrm{DS}}=\frac{A_{1}}{A_{2}}(0<\mathrm{DS}<1)
$$

Where $S$ is the total number of hydrogen atoms for repeat unit of the polymer before sulfonation which is 12 for PEEK, $A_{1}$ is the peak area of the $\mathrm{H}_{13}$ signal for SPEEK and $A_{2}$ is the sum of the peak areas of all the signals $\mathrm{H}_{13}$ for SPEEK. Finally DS should be multiplied by 100 to be expressed by percentage.

The result of the $H$ NMR for SPEEK is presented in Figure 5. From the Figure 5 the $\mathrm{H} 1$,
$\mathrm{H}_{2}, \mathrm{H}_{3}$ and $\mathrm{H}_{4}$ of non-sulfonated repeat units show their characteristic singlet almost at $7.25 \mathrm{ppm}$. The sulfonation process happening at the position where the sulfonic functional group is introduced to the aromatic ring causes this type of protons to differentiate into three categories; $\mathrm{H}_{13}$ (the singlet at almost $7.5 \mathrm{ppm}$ ), $\mathrm{H}_{14}$ (the doublet at almost 7.22 ppm) and $H_{15}$ (the doublets at almost 7.12 ppm). According to the equation 7 and results which are tabulated in Figure 4, the DS was found to be 68.

\subsection{Water Uptake Study at Different Temperatures}

In this study water uptake of all membranes was carried out from room temperature to $80^{\circ} \mathrm{C}$ and the results are summarized in Table 1. From the Table 1, it can be observed that firstly, the water uptake of all membranes increased when temperature increased;this is most likely because of ionic cluster formation. When the temperature is high the sulfonic groups will readily form ion domains, which are hydrophilic and are responsible for the majority of the water uptake [25].

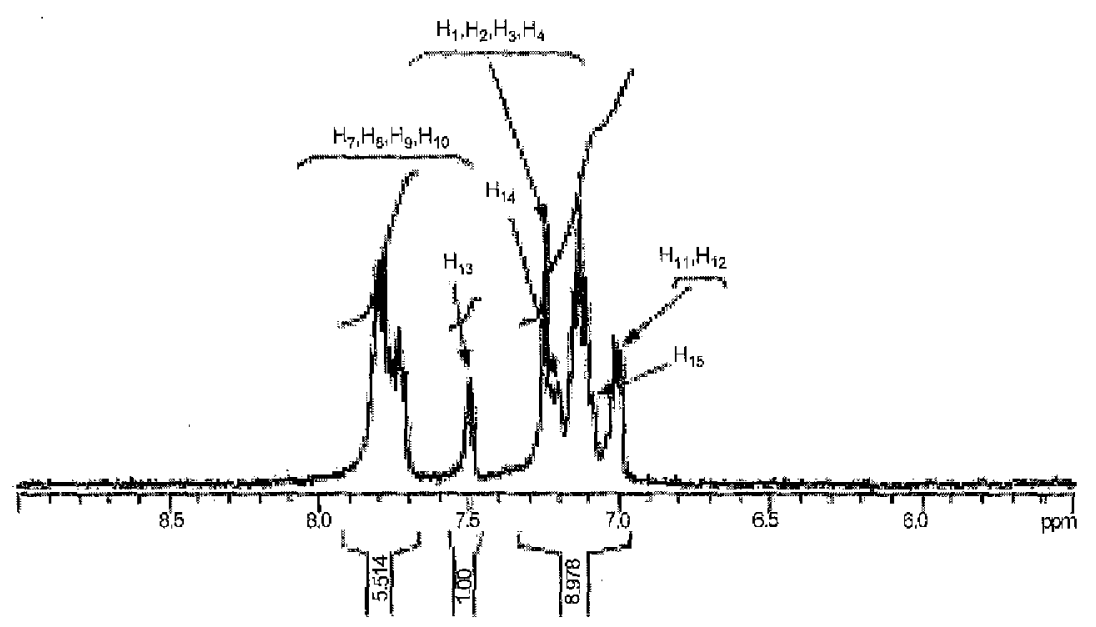

Figure $5 \mathrm{H} \mathrm{NMR}$ spectra of sulfonation at $60^{\circ} \mathrm{C}$ 
Table 1 Water uptake of all SPEEK (68) and SPEEK (68)/CSMM membranes

\begin{tabular}{|c|c|c|c|c|c|c|}
\hline \multirow[t]{2}{*}{ Sample } & \multicolumn{6}{|c|}{ Water uptake \% } \\
\hline & $25^{\circ} \mathrm{C}$ & $40^{\circ} \mathrm{C}$ & $50^{\circ} \mathrm{C}$ & $60^{\circ} \mathrm{C}$ & $70^{\circ} \mathrm{C}$ & $80^{\circ} \mathrm{C}$ \\
\hline 1. SPEEK (68) & 31.87 & 34.73 & 38.6 & 45.5 & 79.35 & 137.42 \\
\hline 2. SPEEK (68)/CSMM & 32.57 & 37.37 & 41.8 & 50.19 & 101.59 & dissolved \\
\hline 3. Nafion 112 & 8.49 & 10.01 & 10.96 & 12.21 & 13.81 & 15.58 \\
\hline
\end{tabular}

Secondly the water uptake of SPEEK (68) and SPEEK (68)/CSMM membranes were considerably more than that of Nafion 112 at each individual temperature, this may be due to the microstructure of the polymers which is distributed in two domains; in SPEEK membrane the hydrophobic/ hydrophilic domain difference is smaller than that of Nafion due to its backbone which is less hydrophobic when its sulfonic acid functional group is less hydrophilic as compared to Nafion [26]. This causes hydrated hydrophilic domain of the SPEEK membranes can be expanded, but in Nafion less branched of its perfluorinated polymer backbone limits the hydrophilic domain hydration [23].

The final trend according to the data is that the SPEEK (68)/CSMM blend membranes showed more water uptake as compared to SPEEK (68) and Nafion 112 at each individual temperature, the reason is due to CSMM which provides more sulfonic acid groups and makes the membrane

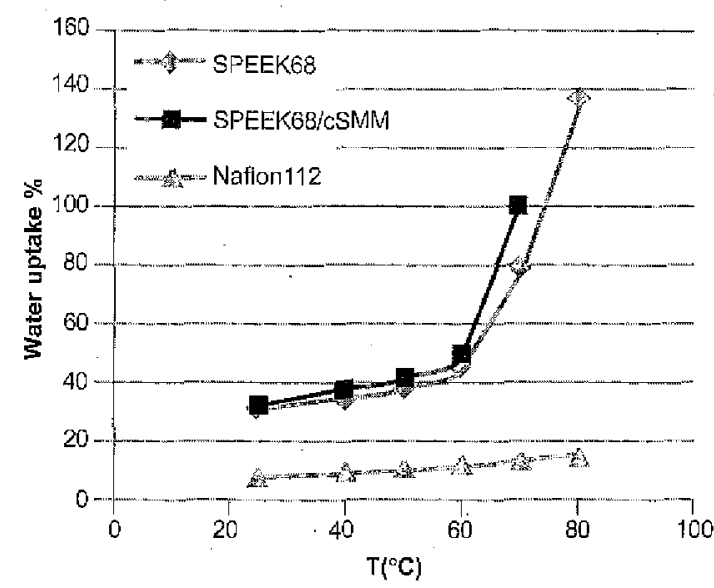

Figure 6 Water uptake of SPEEK68, SPEEK (68)/cSMM andNafion 12 membranes at different temperatures surface more hydrophilic as compared to the SPEEK (68) and Nafion112 [21].

According to the data from the Table 1 water uptake of the SPEEK (68) and SPEEK (68)/CSMM membranes increased significantly at high temperatures. The highest amount of water uptake at each individual temperature was allocated to the SPEEK (68)/CSMM before $80^{\circ} \mathrm{C}(101.29 \%$ at $70^{\circ} \mathrm{C}$ ), on contrary the lowest one was for Nafion 112.

For showing the effect of temperature on water uptake of all membranes better, the water uptake of membranes were plotted versus temperature, as shown in Figure. 6.

\subsection{Proton Conductivity Study at Different Temperatures}

Proton conductivity of SPEFK (68), SPEEK (68)/ cSMM membranes and Nafion 112 was carried out at different temperatures. According to the results which are tabulated in Table 2 the proton conductivity changes with temperatures is as follows. First of all proton conductivity of all membranes increased as the temperature increased, the reason is when temperature increment occurs, consequently rate of proton migration increases, moreover in case of SPEEK (68) and SPEEK (68)/CSMM membranes the dissociation of the sulfonic acid groups increases considerably at high temperatures, however in Nafion112 case the dissociation reaches almost $100 \%$ at room temperature so the increment of proton conductivity mostly is because of proton mobility rate increment for Nafion 112 [11]. Secondly the highest amount of proton conductivity at each individual temperature was for Nafion112 despite of its lower water uptake. The reason is due to the differences between Nafion 112 and SPEEK membranes structure. In 
Table 2 Proton conductivity of SPEEK (68) and SPEEK (68)/cSMM membranes from room to $80^{\circ} \mathrm{C}$

\begin{tabular}{lccccccc}
\hline Sample & \multicolumn{5}{c}{ Proton conductivity (S/cm) } & & \\
& & $25^{\circ} \mathrm{C}$ & $400^{\circ} \mathrm{C}$ & $50^{\circ} \mathrm{C}$ & $60^{\circ} \mathrm{C}$ & $70^{\circ} \mathrm{C}$ & $80^{\circ} \mathrm{C}$ \\
\hline 1. SPEEK (68) & 0.02307 & 0.02992 & 0.03716 & 0.04707 & 0.05695 & 0.06304 \\
2. SPEEK (68)/CSMM & 0.03675 & 0.04449 & 0.04762 & 0.05731 & 0.0638 & - \\
3. Nafion 112 & 0.07086 & 0.07267 & 0.0766 & 0.08098 & 0.09143 & 0.09773 \\
\hline
\end{tabular}

SPEEK membrane the hydrophobic/hydrophilic domain difference is smaller than that of Nafion 1.12 and because of this reason SPEEK possesses narrower channels with dead end and highly branched structure [26], subsequently lower proton conductivity compare to Nafion 112.

Secondly between SPEEK and SPEEK/cSMM membranes at same DS and at each individual temperature the SPEEK/CSMM membrane showed higher proton conductivity; the reason is due to the CSMM which provides more sulfonic acid groups and makes the membrane more hydrophilic and more water uptaeke compare to the SPEEK [21] and finally according to the Table 2 which has been tabulated below the proton conductivity of SPEEK (68)/cSMMdecreased at $80^{\circ} \mathrm{C}$, The reason is due to dissolution and loss of mechanical stability of the membrane at high temperatures [11]. Figure 7 depicts proton conductivity changes over the temperatures clearly.

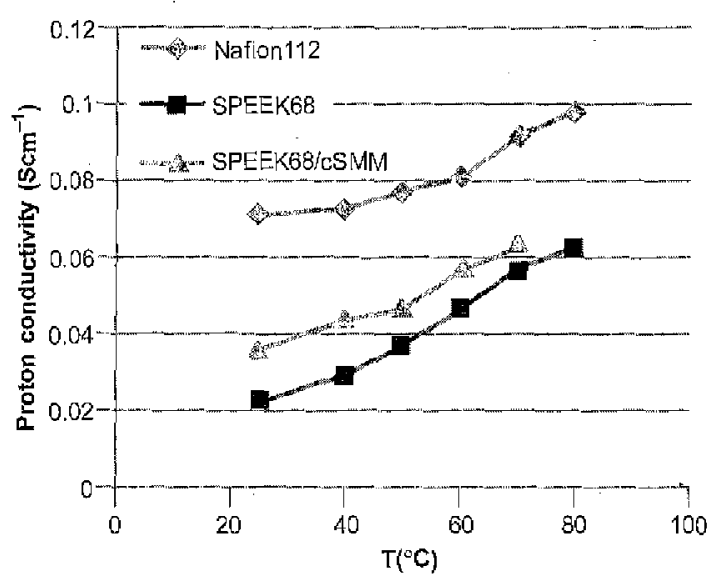

Figure 7 Proton conductivity of SPEEK (68), SPEEK (68)/cSMM, and Nafion112 at different temperatures

\subsection{Methanol Permeability Study at Different Operating Temperatures}

In this study methanol permeability of all membranes was carried out from room temperature to $80^{\circ} \mathrm{C}$ and the results are summarized in Figure 7. From the Figure 8 some observation can be described about the trend of the methanol permeability with the elevated temperature. First of all methanol permeability of all membranes increased when temperature increment occurred, the reason is faster molecular movement due to heat increment and consequently increasing rate of methanol permeability. Secondly according to the Figure 7 the highest methanol permeability was for Nafion $12\left(1.77 \times 10^{-6}\right.$ and $5.52 \times 10^{-6} \frac{\mathrm{cm}^{2}}{\mathrm{~s}}$ at room temperature and $80^{\circ} \mathrm{C}$, respectively). The reason is due to the Nafion 12 and SPEEK structural differences; in Nafion 12 case channels are wider so it is easier

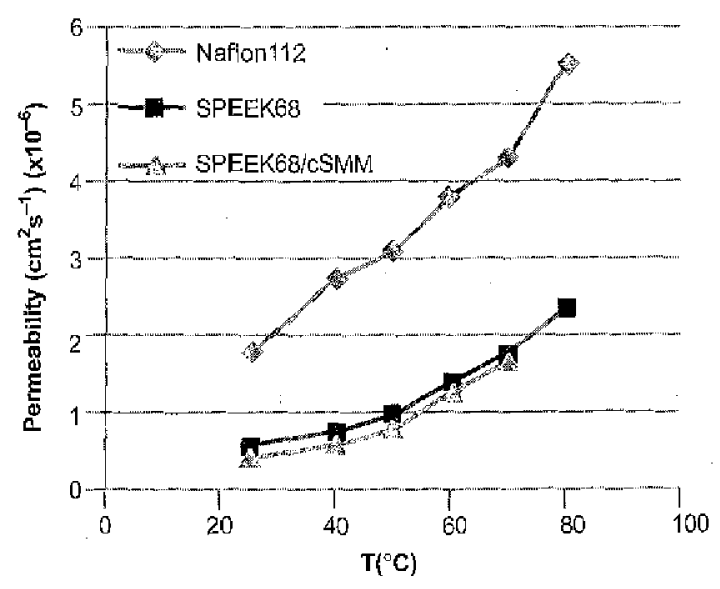

Figure 8 Methanol Permeability versus temperature for SPEEK (68) and SPEEK (68)/CSMM membranes 
for methanol to pass through these channels [23]. Thirdly it can be seen from the Figure 7 that methanol permeability of SPEEK (68)/CSMM membrane was lower in comparison with SPEEK (68) membrane. The reason is methanol permeability mostly occurs via free water inside the interconnected membrane structure channels and trivially via non-freezing bound water associated with the ionic sites, since the addition of cSMM reduces the free water content, probably due to the reduction in the size of the interconnected channels, decreased in methanol permeability seems natural [21].

\subsection{Overall Membranes Characteristics}

The overall performance for membranes was calculated at $60^{\circ} \mathrm{C}$. According to the Figure 9 which is illustrated, SPEEK (68)/CSMM membrane showed higher overall performance $\left(4.51 \times 10^{4}\right)$ at $60^{\circ} \mathrm{C}$, while the lowest one was allocated to Nafion1 $12\left(2.12 \times 10^{4}\right)$. Decrement in methanol permeability and at the same time increment in proton conductivity causes cell efficiency and power density to increase[4], so the blended membrane has potential to be used in DMFC instead of Nafion 112 due to its higher overall performance.

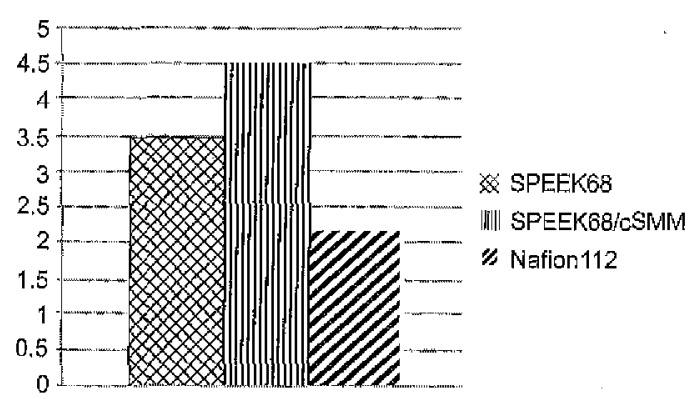

Figure 9 Overall performance of SPEEK (68), SPEEK (68)/cSMM, and Nafion 112 membranes at $60^{\circ} \mathrm{C}$

\subsection{CONCLUSION}

SPEEK (68)/CSMM membrane showed better behavior compared to other membranes over the temperature range before $80^{\circ} \mathrm{C}$. Water uptake of the blended membrane showed improvement compared to SPEEK (68) and Nafion 12. Furthermore proton conductivity also was higher as compared to SPEEK (68), but still lower than that of Nafion112. Moreover methanol permeability of SPEEK (68)/CSMM was lower than SPEEK (68) and Nafion 12 and finally the highest overall performance at $60^{\circ} \mathrm{C}$ also was allocated to SPEEK (68)/CSMM. These results indicate that SPEEK (68)/CSMM membrane is promising to be used as a proton exchange membrane in direct methanol fuel cell.

\section{REFERENCES}

[1] N. Zhang, G. Zhang, D. Xu, C. Zhao, W. Ma, H. Li, Y. Zhang, S. Xu, H. Jiang, H. Sun and H. Na. 2011. Cross-linked Membranes based on Sulfonated Poly (ether ether ketone) (SPEEK)/Nafion for Direct Methanol Fuel Cells (DMFCs). International Journal of Hydrogen Energy. 36(17): 11025-11033.

[2] J. J. Hwang, W. R. Chang, F. B. Weng, A. Su and C. K. Chen. 2008. Development of a Small Vehicular PEM Fuel Cell System. International Jounal of Hydrogen Energy. 33(14): 3801-3807.

[3] T. H. Nguyen, C. Wang and X. Wang. 2009. Pore-filling Membrane for Direct Methanol Fuel Cells Based on Sulfonated Poly (Styreneran-ethylene) and Porous Polyimide Matrix. Journal of Membrane Science, 342(1-2): 208-214.

[4] N. H. B. Othman. 2009. Synthesis, Characterization and Optimization of Sulfonated Polyether Ether Ketone Composite Membrane for Direct Methanol Fuel Cell. University Technology Malaysia.

[5] G. Gnana Kumar, A. R. Kim, K. Suk Nahm and R. Elizabeth. 2009. Nafion Membranes Modified with Silica Sulfuric Acid for the Elevated Temperature and Lower Humidity Operation of PEMFC. International Journal of Hydrogen Energy. 34(24) : 9788-9794.

[6] H. Hou, G, Sun, Z. Wu, W. Jin and Q. Xin. 2008, Zirconium Phosphate/Nafion 115 Composite Membrane for Highconcentration DMFC. International Journal of Hydrogen Energy. 33(13): 3402-3409. 
[7] E. H. Jung, U. H. Jung, T. H. Yang, D. H. Peak, D. H. Jung and S. H. Kim. 2007. Methanol Crossover Through PtRu/Nafion Composite Membrane for a Direct Methanol Fuel Cell. International Journal of Hydrogen Energy. 32(7): 903-907.

[8] G.-B. Jung, F.-B. Weng, A. Su, J.-S. Wang, T. Leon Yu, H.-L. Lin, T.-F. Yang and S.-H. Chan. 2008. Nafion/PTFE/silicate Membranes for High-temperature Proton Exchange Membrane Fuel Cells. International Journal of Hydrogen Energy. 33(9): 2413-2417.

[9. U. Sen, S. Ünügür Çelik, A. Ata and A. Bozkurt. 2008. Anhydrous Proton Conducting Membranes for PEM Fuel Cells Based on Nafion/Azole Composites. International Journal of Hydrogen Energy. 33(11): 2808-2815.

[10. V. Neburchilov, J. Martin, H. Wang and J. Zhang. 2007. A Review of Polymer Electrolyte Membranes for Direct Methanol Fuel Cells. Journal of Power Sources. 169(2): 221-238.

[11] Q. Gao, Y. Wang, L. Xu, Z. Wang and G. Wei. 2009. Proton-exchange Sulfonated Poly (ether ether ketone)/Sulfonated Phenolphthalein Poly (ether sulfone) Blend Membranes in DMFCs. Chinese Journal of Chemical Engineering. 17(6): 934-941.

[12] J. Jaafar, A. F. Ismail, T. Matsuura and K. Nagai. 2011. Performance of SPEEK based Polymer-nanoclay Inorganic Membrane for DMFC. Journal of Membrane Science. 382(1-2): 202-211.

[13] S. D. Mikhailenko, S. M. J. Zaidi and S. Kaliaguine, 2001. Sulfonated Polyether Ether Ketone based Composite Polymer Electrolyte Membranes. Catalysis Today, $67(1-3): 225-236$.

[14] S. P. Nunes, B. Ruffmann, E. Rikowski, S. Vetter and K. Richau. 2002. Inorganic Modification of Proton Conductive Polymer Membranes for Direct Methanol Fuel Cells. Journal of Membrane Science. 203(1-2): 215-225.

[15] M. H. D. Othman, A. F. Ismail and A. Mustafa. 2007. Proton Conducting Composite Membrane from Sulfonated Poly (ether ether ketone) and Boron Orthophosphate for Direct Methanol Fuel Cell Application. Journal of Membrane Science. 299(1-2): 156-165.

[16] D. Rana, T. Matsuura and R. M. Narbaitz. 2006. Novel Hydrophilic Surface Modifying Macromolecules for Polymeric Membranes: Polyurethane Ends Capped by Hydroxy Group. Journal of Membrane Science. 282(1-2): 205-216.

[17] D. Rana, T. Matsuura, R. M. Narbaitz and C. Feng, 2005. Development and Characterization of Novel Hydrophilic Surface Modifying Macromolecule for Polymeric Membranes. Journal of Membrane Science. 249(1-2): 103-112.

[18] D. E. Suk, T. Matsuura, H. B. Park and Y. M. Lee. 2006. Synthesis of a New Type of Surface Modifying Macromolecules (nSMM) and Characterization and Testing of $\mathrm{nSMM}$ Blended Membranes for Membrane Distillation. Journal of Membrane Science. 277(1-2): 177-185.

[19] P. Xing, G. P. Robertson, M. D. Guiver, S. D. Mikhailenko, K. Wang and S. Kaliaguine. 2004. Synthesis and Characterization of Sulfonated Poly (ether ether ketone) for Proton Exchange Membranes. Journal of Membrane Science. 229(1-2): 95-106.

[20] S. M. J. Zaidi, S. D. Mikhailenko, G. P. Robertson, M. D. Guiver and S. Kaliaguine. 2000. Proton Conducting Composite Membranes from Polyether Ether Ketone and Heteropolyacids for Fuel Cell Applications. Journal of Membrane Science. 173(1): 17-34.

[21] M. N. a. M. Norddin, A. F. Ismail, D. Rana, T. Matsuura, A. Mustafa and A. TabeMohammadi. 2008. Characterization and Performance of Proton Exchange Membranes for Direct Methanol Fuel Cell: Blending of Sulfonated Poly (ether ether ketone) with Charged Surface Modifying Macromolecule. Journal of Membrane Science. 323(2): 404-413.

[22] M. M. Nasef, N. A. Zubir, A. F. Ismail, K. Z. M. Dahlan, H. Saidi and M. Khayet. 2006. Preparation of Radiochemically Pore-filled Polymer Electrolyte Membranes for Direct 
Methanol Fuel Cells. Journal of Power Sources. 156(2): 200-210.

[23] J. Jaafar, A. F. Ismail and A. Mustafa. 2007. Physicochemical Study of Poly (ether ether ketone) Electrolyte Membranes Sulfonated with Mixtures of Fuming Sulfuric Acid and Sulfuric Acid for Direct Methanol Fuel Cell Application. Materials Science and Engineering: A. 460-461(0): 475-484.

[24] S. M. J. Zaidi. 2003. Polymer Sulfonation A Versatile Route to Prepare Proton Conducting Membrane Material for
Advanced Technologies. Arabian Journal for Science and Engineering. 28(2B); 183-194. [25] S. Zhong, X. Cui, H. Cai, T. Fu, C. Zhao and H. Na. 2007. Crosslinked Sulfonated Poly(ether ether ketone) Proton Exchange Membranes for Direct Methanol Fuel Cell Applications. Journal of Power Sources. 164(1): 65-72.

[26] K. K. D. 2001. On the Development of Proton Conducting Polymer Membranes for Hydrogen and Methanol Fuel Cells. Journal of Membrane Science. 185(1): 29-39. 